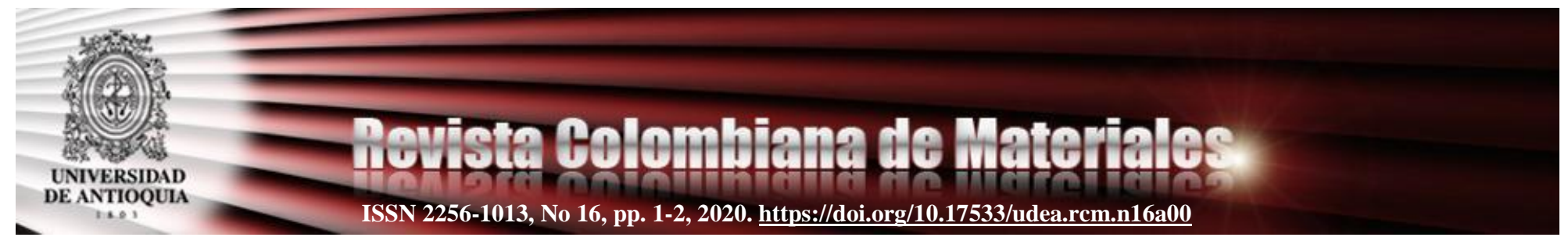

\title{
EDITORIAL: \\ UNA VISIÓN DEL ESTATUS ACTUAL DE LAS PRÓTESIS ORTOPÉDICAS DESDE MÉXICO
}

\author{
J. Henao ${ }^{1 *}$, A. Giraldo-Betancur ${ }^{2}$ \\ 1: Catedrático CONACYT-CIATEQ, Av. Manantiales 23a , El marqués, Querétaro, Qro., C.P. 76246, México. \\ 2: Catedrática CONACYT- Centro de Investigación y de Estudios Avanzados del IPN, Unidad Querétaro, \\ Querétaro, Qro. C.P., 76230, México. \\ *jhenao@ conacyt.mx
}

El presente volumen de la Revista Colombiana de Materiales aborda la problemática de las prótesis ortopédicas y los avances de la ciencia e ingeniería de materiales, diseño e ingeniería biomédica en pro de aportar a mejorar este tipo de dispositivos para pacientes de la región. En particular, el presente volumen compila una serie de trabajos presentados en el " 1 er Simposio Nacional de Prótesis Ortopédicas en México: El Estatus Actual" celebrado del 21 al 24 de septiembre de 2020 en Querétaro, México y con divulgación virtual. El evento fue organizado por catedráticos del Consejo Nacional de Ciencia y Tecnología (CONACYT) en México y apoyado por varias instituciones de la región. El evento buscó generar un espacio para que, a través de exposiciones y paneles de discusión, se definiera el estatus actual de las prótesis ortopédicas en México, y se crearan sinergias que permitieran un acercamiento entre la comunidad académica, el sector privado y de gobierno, para facilitar e impulsar el crecimiento de la ciencia y tecnología de las prótesis ortopédicas en la región.

La capacidad científica desarrollada en los centros CONACYT y sus colaboraciones estratégicas en México, a través de los años ha sido clave para identificar oportunamente la problemática relacionada con las prótesis ortopédicas, y se han generado avances científicos y tecnológicos en el campo de la modificación superficial, la personalización, la búsqueda de nuevos componentes y en el diseño de prótesis. Algunos estudios realizados indican que en las últimas 3 décadas los trastornos musculoesqueléticos en humanos han sido causa de discapacidad en México. Así mismo, que el total de años de vida en promedio con este tipo de trastornos se ha incrementado del $10,96 \%$ al $14 \%$ en los últimos 20 años [1]. Si consideramos la esperanza de vida del mexicano promedio de 75 años [2], esto equivaldría a vivir con dicha discapacidad en promedio 9 años de vida. En México, los trastornos musculoesqueléticos representan una de las primeras causas de discapacidad para el grupo de personas de 60 o más años de edad y quienes poseen este tipo de trastornos, los tienen que padecer entre el 13 y el $27 \%$ de los años vividos [3]. Esto es y continuará siendo un importante problema de salud pública en México, que tiene repercusiones económicas importantes si se tiene en cuenta que el porcentaje de población adulta mayor de 50 años será alrededor del $43.3 \%$ para 2050 , lo que representa alrededor de 64 Millones de personas con probabilidad de presentar afecciones musculoesqueléticas [4]. Este panorama podría ser similar en 
varios países de Latinoamérica debido a la expectativa de vida de la población adulta.

Aunque los trabajos publicados en el presente volumen de la Revista Colombiana de Materiales parten de una iniciativa en México, se busca difundirlos a nivel de Latinoamérica, en donde actualmente se divulga la Revista, con el fin de crear sinergias y acercamientos entre la comunidad académica y médica, que permitan impulsar el crecimiento de la ciencia y la tecnología de las prótesis en los diferentes países de la región, que hoy en día ven como una necesidad y/o vislumbran las afecciones muscolesqueléticas como un problema de salud pública. Así mismo, se espera contribuir desde la ciencia e ingeniería de materiales a la solución de la problemática identificada en las prótesis ortopédicas.

\section{REFERENCIAS}

[1] Lozano, R., Gómez-Dantés, H., GarridoLatorre, F., Jiménez-Corona, A., Campuzano-Rincón, J. C., Franco-Marina, F., \& Murray, C. J. (2013). La carga de enfermedad, lesiones, factores de riesgo y desafíos para el sistema de salud en México. Salud pública de México, 55(6), 580-594. http://dx.doi.org/10.21149/spm.v55i6.7304

[2] Boletín No. 295/2019. [Internet:https://www.gob.mx/segob/prensa/i nforma-conapo-sobre-la-esperanza-de-vidade-la-poblacion-mexicana.]. [Acceso 19 de Enero 2021]. Ciudad de México: Secretaría de Gobernación.

[3] Gutiérres-Robledo, L. M., García-Peña, C., Medina-Campos, R., Parra-Rodriguez, L., Lopez-Ortega, M., \& Gonzalez-Meljem, J. M. (2018). Estudio de carga de la enfermedad en personas adultas mayores: un reto para México.

[Internet: http://www.geriatria.salud.gob.mx/].[Acceso Ene 2021]. Ciudad de México: Secretaría de Salud, Instituto Nacional de Geriatría.

[4] CONAPO México. [Internet:https://www.conapo.gob.mx/work/ models.]. [Acceso 19 de Enero 2021]. Ciudad de México: Consejo Nacional de Población. 